\title{
The origin of the vertebrate jaw: Intersection between developmental biology-based model and fossil evidence
}

\author{
GAI ZhiKun \& ZHU Min* \\ Key Laboratory of Evolutionary Systematics of Vertebrates, Institute of Vertebrate Paleontology and Paleoanthropology, Chinese Academy of \\ Sciences, Beijing 100044, China
}

Received May 8, 2012; accepted May 29, 2012; published online August 7, 2012

\begin{abstract}
The origin of the vertebrate jaw has been reviewed based on the molecular, developmental and paleontological evidences. Advances in developmental genetics have accumulated to propose the heterotopy theory of jaw evolution, i.e. the jaw evolved as a novelty through a heterotopic shift of mesenchyme-epithelial interaction. According to this theory, the disassociation of the nasohypophyseal complex is a fundamental prerequisite for the origin of the jaw, since the median position of the nasohypophyseal placode in cyclostome head development precludes the forward growth of the neural-crest-derived craniofacial ectomesenchyme. The potential impacts of this disassociation on the origin of the diplorhiny are also discussed from the molecular perspectives. Thus far, our study on the cranial anatomy of galeaspids, a 435-370-million-year-old 'ostracoderm' group from China and northern Vietnam, has provided the earliest fossil evidence for the disassociation of nasohypophyseal complex in vertebrate phylogeny. Using Synchrotron Radiation X-ray Tomography, we further show some derivative structures of the trabeculae (e.g. orbitonasal lamina, ethmoid plate) in jawless galeaspids, which provide new insights into the reorganization of the vertebrate head before the evolutionary origin of the jaw. These anatomical observations based on new techniques highlight the possibility that galeaspids are, in many respects, a better proxy than osteostracans for reconstructing the pre-gnathostome condition of the rostral part of the braincase. The cranial anatomy of galeaspids reveals a number of derived characters uniquely shared with gnathostomes. This raises the potential possibility that galeaspids might be the closest jawless relatives of jawed vertebrates. Our study provides an intriguing example of intersection between developmental biology-based model and fossil evidence.
\end{abstract}

jaw, agnathans, gnathostomes, galeaspids, trabecula, evolutionary developmental biology

Citation: Gai Z K, Zhu M. The origin of the vertebrate jaw: Intersection between developmental biology-based model and fossil evidence. Chin Sci Bull, 2012, 57: 3819-3828, doi: 10.1007/s11434-012-5372-Z

The invention of the jaw appears to be a crucial innovation and perhaps the most profound and radical evolutionary step in the vertebrate history [1,2]. The importance of this invention is obvious, as the jaw allows vertebrates to become 'superpredators' at the top of the food chain $[3,4]$, and subsequently gnathostomes (jawed vertebrates) expanded to occupy a broad range of ecological niches and account for $99.8 \%$ of vertebrate diversity today [5]. However, the sequence leading to the evolutionary origin of the jaw is still enigmatic largely due to the absence of data on the ancestral, intermediate condition [6]. Hagfishes and lampreys are the

*Corresponding author (email: zhumin@ivpp.ac.cn) only living jawless vertebrates (cyclostomes) which are generally considered as the sister group of crown gnathostomes $[7,8]$. Their phylogenetic position makes them critical to understand the emergence of novelties at the agnathan-gnathostome transition [9]. However, due to the large morphological gap between extant jawless and jawed vertebrates [10], the living cyclostomes actually provide little information about the profound reorganization of the vertebrate skull and body plan that occurred along with the origin of the jaw [11].

The extinct armoured jawless vertebrates, or 'ostracoderms', are regarded as precursors of jawed vertebrates [12-16] ('Ostracoderms', Figure 1) and provide insights into this formative episode in vertebrate evolution [11]. For 


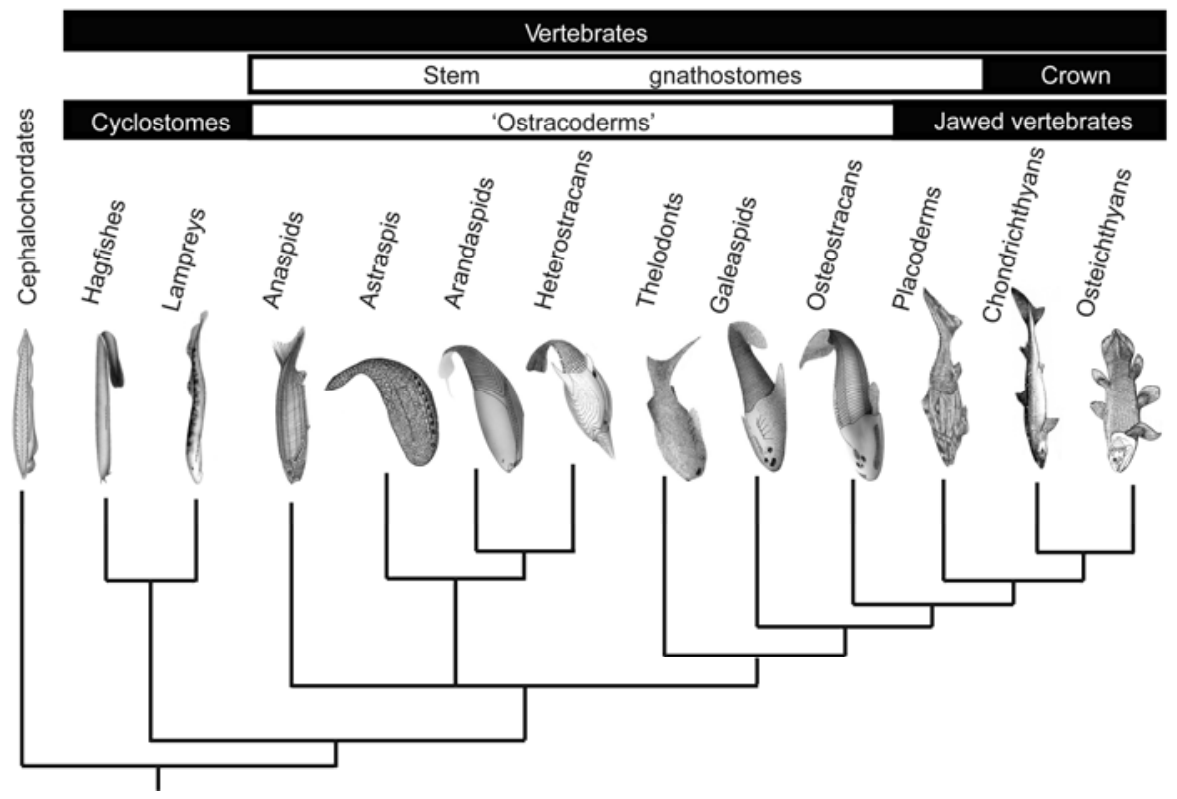

Figure 1 Phylogenetic framework of vertebrates. The monophyly or paraphyly of cyclostomes (hagfishes and lampreys) has been the subject of heated debate for over a century. As the jawless 'ostracoderms' are closer to jawed vertebrates than cyclostomes, they fall into the total-group gnathostomes. In other words, the 'ostracoderms' are stem gnathostomes (note the distinction between gnathostomes and jawed vertebrates: the jawed vertebrates only include placoderms and the crown-group gnathostomes). Modified from [7,16].

example, these extinct bony jawless vertebrates provide some evidence that many features, which are present in extant gnathostomes but absent in cyclostomes, such as the exoskeleton, perichondral bone, sclerotic ring, pectoral fins, and epicercal tail, have been acquired before the origin of the jaw $[12,17]$. However, none of them shows any structure that would possibly foreshadow a mandibular arch of the gnathostome type, i.e., with a palatoquadrate and a Meckelian cartilage [10]. In addition, as the visceral arches in extant cyclostomes and jawed vertebrates are positioned differently relative to the gill filaments (lateral in the former, but medial in the latter), the homology of visceral arches between jawless and jawed vertebrates had been a century-long heated debate [10,18-24]. In a sense, the origin of the jaw appears to be a sudden event in vertebrate evolution, probably lacking an ancestral, intermediate condition like the origin of the horizontal semicircular canal of the inner ear [25].

In a somewhat different field from the comparative anatomy of jawless and jawed vertebrates (searching for the ancestral, intermediate condition of jaws) [10,26], a series of advances in molecular, developmental and embryological studies have accumulated to present a new scenario for the developmental origin of the jaw. Kuratani and his collaborators proposed the heterotopy theory of the jaw evolution on the basis of the developmental genetics of the lamprey and gnathostome head $[6,27-32]$. Their theory assumes that the disassociation of the nasohypophyseal complex for the development of trabecula is a fundamental prerequisite for the origin of the jaw. Accordingly, the appearance of the diplorhiny and trabecula should have preceded that of the jaw $[6,27-31]$. The disassociation of the nasohypophyseal complex is also regarded as a major event for the origin of diplorhiny [10,12,13], possibly allowing the $H h$ gene family to establish the lateral position of the nasal sacs. Recently, our studies on the cranial anatomy of galeaspids, a 435370-million-year-old 'ostracoderm' group from China and northern Vietnam [33], have provided the earliest fossil evidence for the disassociation of nasohypophyseal complex in vertebrate phylogeny [11]. Using Synchrotron Radiation $\mathrm{X}$-ray Tomography, here, we further show that some derivative structures of the trabeculae (e.g. orbitonasal lamina, ethmoid plate) are also present in galeaspids. This indicates that galeaspids at least partly possessed the true trabeculae as in jawed vertebrates. The trabeculae cranii of jawed vertebrates has long been regarded as a major developmental advance over agnathans [34]. Previously, discussions on whether the trabecula is present in the jawless ancestors of gnathostomes mainly relied on the developmental biologybased model because for lack of relevant fossil evidence. The identification of trabecula-derived structures in jawless galeaspids sheds new light on the reorganization of the vertebrate head before the evolutionary origin of the jaw. Our study discusses the potential bearings of galeaspid head innovation on the vertebrate phylogeny, and provides an intriguing example of intersection between developmental biology-based model and fossil evidence.

\section{Developmental model for the origin of the vertebrate jaw: the heterotopy theory}

The vertebrates are characterised by the presence of the 
neural crest and the placodes which provide the basis for the formation of a new head (e.g. paired sensory organs, trabeculae cranii) and visceral skeleton $[35,36]$. The comparative embryology of lampreys and gnathostomes indicates that the initial distribution of neural crest cells is conserved in both groups. From rostral to caudal, three distinct populations of neural crest cells - the trigeminal, hyoid and branchial crest cells - can be distinguished at the stage of pharyngula (pink, yellow and green, Figure 2(a),(b)) [27,37]. The trigeminal crest cells (pink, Figure 2(a),(b)) are distributed mainly in the region rostral to the first pharyngeal pouch (PA1, Figure 2(a),(b)). They can be further subdivided into the premandibular crest cells (pmc, Figure 2(c)-(f)) and the mandibular crest cells (mc, Figure 2(c)-(f)) which are the basic materials differentiating into the oral supporting apparatus (e.g. the jaw) [6,27,37].

The patterning of visceral arches including mandibular arch can be viewed as the neural crest cells in a Cartesian grid of the regulatory gene expression (Figure 2(a),(b)) [31]. Hox genes, a specific class of homeobox, are expressed along the antero-posterior axis of the embryonic pharynx. Through a nested pattern of Hox gene expression, each pharyngeal arch acquires its positional value to differentiate into specific morphology (Hox, Figure 2(a),(b)). In gnathostomes, the jaw is differentiated from the first pharyngeal arch (PA1, Figure 2(b)), which is characterised by the Hox code default state (no Hox genes expressed in mandibular arch) [27,38]. Cohn [39] reported that one of the Hox genes, HoxL6, is expressed in the mandibular arch of lampreys, and suggested that loss of Hox expression from the mandibular arch of gnathostomes may have facilitated the invention of the jaw. However, more recent observations in lamprey Lethenteron japonicum revealed no Hox cognate expresssion in the mandibular ectomesenchyme at any stage of development [38]. Kuratani [28] considered that the Hox-default state in mandibular arch is still important for the origin of the jaw (e.g. allowing the trigeminal ectomesenchyme to vary its range easily without the constraints of Hox code), and this default state was probably established in the common ancestor of lampreys and gnathostomes.

Similarly, $D l x$ genes are expressed in a dorso-ventral nested pattern to differentiate the dorsoventral pattern of each visceral arch in gnathostomes (Dlx, Figure 2(b)) [40]. However, such nested expression of $D l x$ genes has not been detected in lampreys (Dlx, Figure 1(a)). Compared to the $H o x$-code default, the nested expression of $D l x$ genes can be observed in the madibular arch of gnathostomes [40]. With the aid of homeobox genes such as Dlx and Msx (the oral patterning program), the trigeminal ectomesenchyme differentiates into the oral supporting apparatus in lampreys and gnathostomes. According to the heterotopy theory [30], the jaw evolution has involved a caudal shift of the oral patterning program (e.g. Dlx, Msx and their growth factors FGF and BMP, Figure 2(c),(d)). In lampreys, the oral patterning program is expressed in both the mandibular and premandibular ectomesenchyme (Dlx, FGF8, BMP4, Figure 2(c)). Thus, the premandibular ectomesenchyme differentiates into the upper lip (ulp, Figure 2(a),(c)), and the mandibular ectomesenchyme differentiates into the lower lip and velum (llp, vel, Figure 2(a),(c)). By contrast, in gnathostomes, the oral patterning program is restricted to the mandibular region (Dlx, FGF8, BMP4, Figure 2(d)), thus only the mandibular ectomesenchyme differentiates into the oral apparatus (mx, mn, Figure 2(b),(d)). The premandibular ectomesenchyme that used to differentiate as the agnathan upper lip (ulp, Figure 2(a),(c),(e)) is now utilized to form the gnathostome trabecula (tr, Figure 2(d),(f)). Consequently, the jaw evolved as an evolutionary novelty through tissue rearrangements and a heterotopic shift of mesenchymeepithelial interaction [27].

\section{Disassociation of the nasohypophyseal complex as a fundamental prerequisite for the origin of the jaw}

According to the heterotopy theory [6,27-31], the heterotopic shift of tissue interaction should have taken place after the acquisition of the diplorhiny and trabecula. A substantial distinction in the head structures of cyclostomes, in comparison with gnathostomes, is the presence of a single median duct, or 'nostril' (no, Figure 3(a),(b)), leading to the nasohypophyseal organ (na, hy.d, Figure 3(a),(b)), which develops from a single median nasohypophyseal placode (nhp, Figure 2(e)). By contrast, gnathostomes possess the paired separate nasal sacs (na, Figure 3(e)) with individual externalized nostrils (no, Figure 3(e)) and independent hypophyseal organ (hy.d, Figure 3(e)). These three structures developed from three independent placodes, the paired laterally faced nasal placodes (np, Figure 2(f)) and the Rathke's pouch (Rp, Figure 2(f)). Such placodal morphology allows premandibular crest cells (pmc, Figure 2(f)) of gnathostomes to grow rostrally to form the trabecula, and the mandibular ectomesenchyme (mc, Figure 2(f)) to grow anterolaterally to form the jaw. However, in lampreys, the rostral growth of the premandibular neural crests (pmc, Figure 2(e)) is precluded by the median nasohypophyseal placode. Thus, the invention of the jaw firstly required the disassociation of the nasohypophyseal placode for the development of trabecula. Kuratani [27] speculated that the jawless ancestors of gnathostomes may be found in the forms with paired nostrils and trabecula in the fossil record.

\section{Hedgehog $(\mathrm{Hh})$ gene family and the separation of nasal sacs}

The disassociation of the nasohypophyseal complex is also regarded as a major event for the evolutionary origin of the diplorhiny (nasal sacs with individual externalized nostrils) 

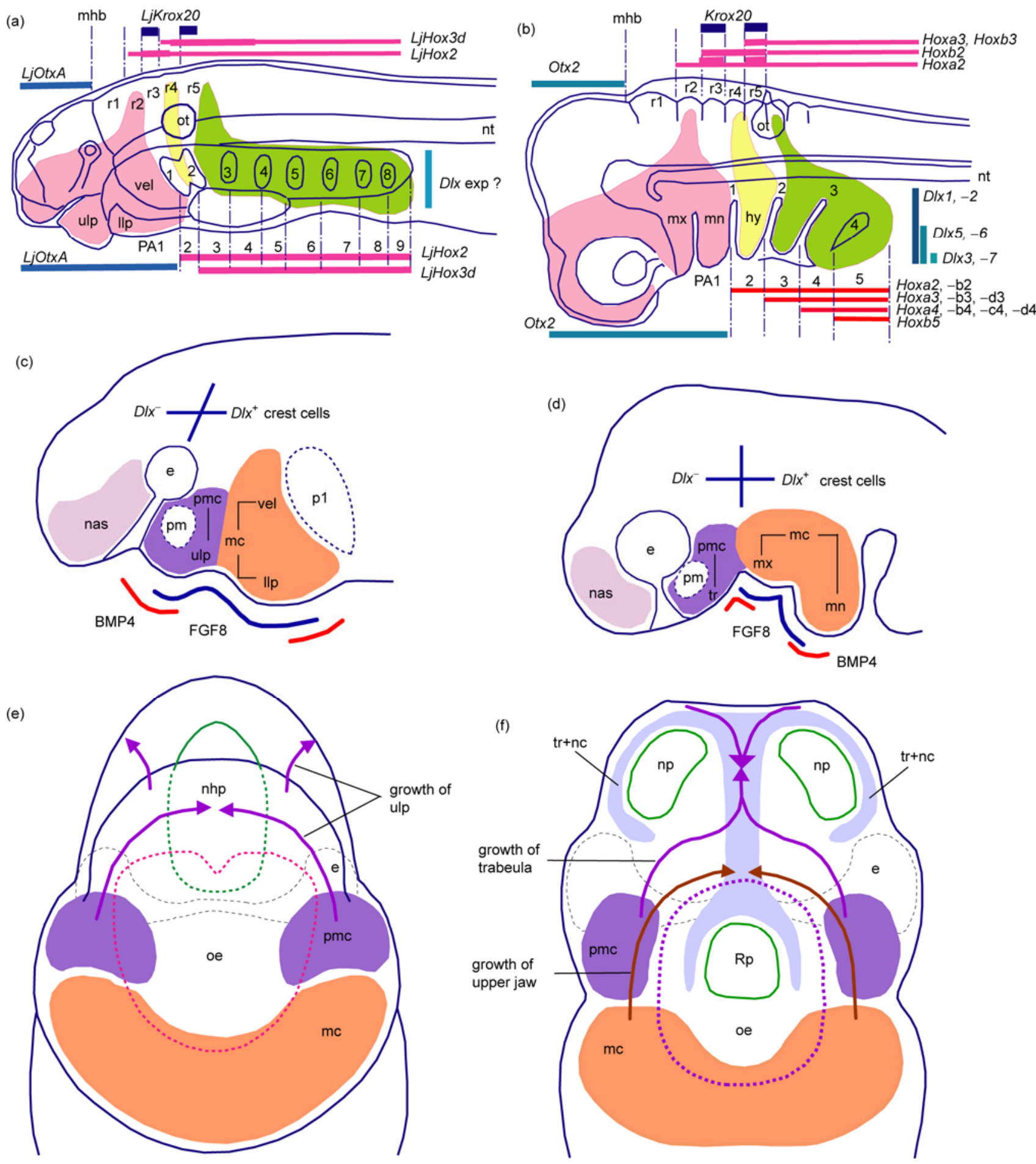

Figure 2 The comparative embryology of lampreys and gnathostomes. (a)-(b) Initial distribution of neural crest and the gene expression patterns of lampreys (a) and gnathostomes (b); pink, yellow, and green: trigeminal, hyoid, and branchial crest cells population, from Kuratani [27, fig. 3A]. (c)-(d) Distribution patterns of trigemnal crest cells and oral patterning program of lampreys (c) and gnathostomes (d), showing that the oral patterning program $D l x, M s x$ and their growth factors FGF8 and BMP4 have a caudal shift in gnathostomes, from Shigetani et al. [30, fig. 3A-D]. (e)-(f) Topographical relationships between oral ectoderm, nasohypophyseal complex and trigemnal crest cells in lampreys (e) and gnathostomes (f), from Kuratani [27, fig. 5C] and Kuratani et al. [6, fig. 9a]. In gnathostomes, the premandibular crest cells ( $\mathrm{pmc}$ ) grow rostrally between the Rathke's pouch (Rp) and the paired nasal placodes (np) to form a part of the trabecular cartilage (tr). The mandibular crest cells (mc) grow antero-rostrally to form the upper jaw halves that fuse in front of the hypophysis. In lampreys, the rostral growth of the premandibular crest cells (pmc) is precluded by the nasohypophyseal plate (nhp) to form the upper lip. BMP, bone morphogenetic factor; e, eye; FGF, fibroblast growth factor; hy, hyoid arch; llp, lower lip; mc, mandibular crest cells; mhb, mid-hindbrain boundary; $\mathrm{mn}$, mandibular process; mx, maxillary process; nas, nasal region; nc, nasal capsules; nhp, nasohypophyseal plate; np, nasal placodes; nt, notochord; oe, oral ectoderm; ot, otic vesicle; PA, pharyngeal arches; pm, premandibular mesoderm; pmc, premandibular crest cells; r1-r5, rhombomeres; Rp, Rathke's pouch; tr, trabecular cartilage; ulp, upper lip; vel, velum; 1-8, pharyngeal slits or pouches. 

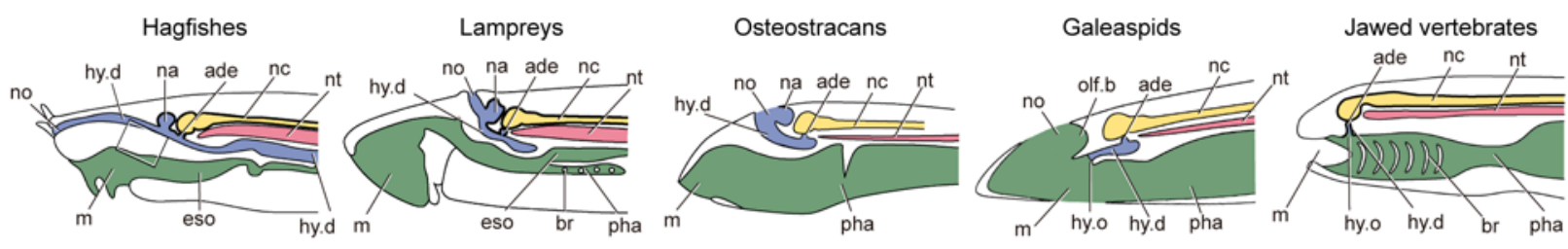

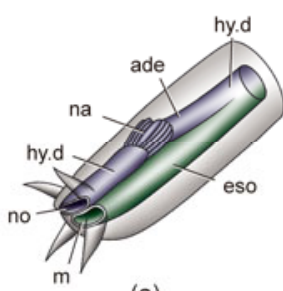

(a)

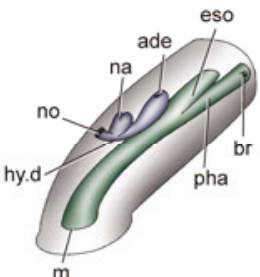

(b)

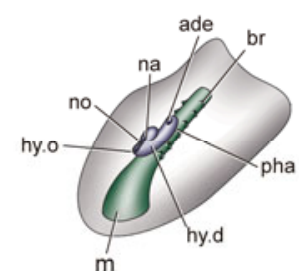

(c)

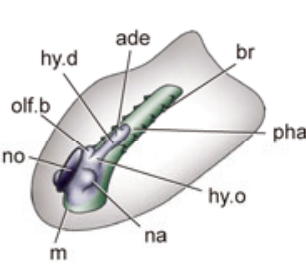

(d)

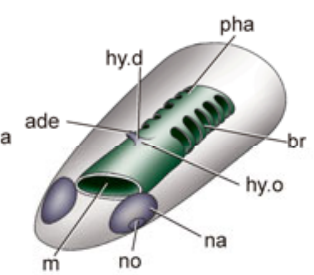

(e)

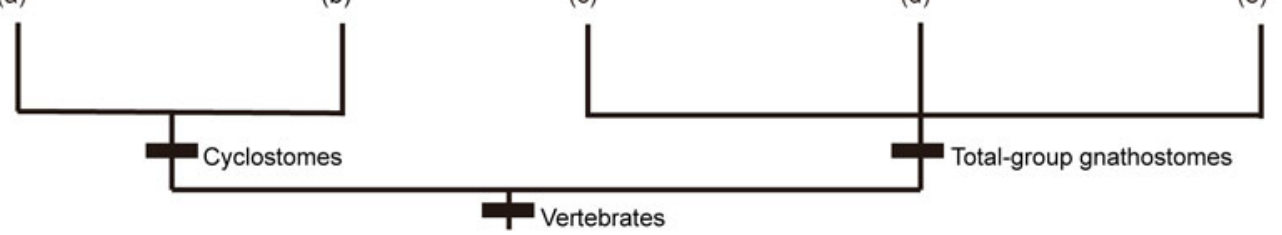

Figure 3 The early evolution of nasohypophyseal complex. Galeaspids are, in many ways, a better proxy than osteostracans for reconstructing the pregnathostome condition of the rostral part of the braincase. This raises the potential possibility that galeaspids might be the closest jawless relatives of jawed vertebrates, modified from [11]. ade, adenohypophysis; br, branchial duct or slit; eso, oesophagus; hy.d, hypophyseal or buccohypophyseal duct; hy.o, hypophyseal opening; m, mouth; nc, neural cord; na, nasal sacs; no, nostril; nt, notochord; olf.b, olfactory bulb; pha, pharynx.

at the agnathan-gnathostome transition [10,12,13]. Some advances in evolutionary developmental biology might provide molecular insights into the potential impacts of this event on the origin of the diplorhiny. The Hedgehog $(H h)$ gene family plays a critical role in regulating vertebrate organogenesis and patterning almost every aspect of the vertebrate body plan [41]. A striking aspect of $H h$ function is its role in establishing cell fates and gene expression patterns characteristic of the ventral midline throughout the neural tube [42]. In mice $S h h$ mutant embryos $\left(S h h^{--}\right)$, the normally paired lateral structures such as the telencephalon, the mandibular and maxillary arches, the optic vesicles and the nasal placodes are fused to form a single structure in midline [42,43]. This phenotype is collectively known as holoprosencephaly, which is accompanied by cyclopia, fused single nasal chamber, fused single telencephalic vesicle, and other forebrain and facial midline defects $[42,43]$. Intriguingly, the fused nasal chamber in Shh mutant mice embryos [43] is reminiscent of the monorhiny in jawless vertebrates. Recently, the previously unreported $H h$ expression in the nasohypophyseal plate was observed in lampreys [44] (Figure 4). This probably indicates that the molecular mechanism separating the nasal sacs has been established in the common ancestor of lampreys and gnathostomes (Figure $4)$. In hagfishes and lampreys, the olfactory organs developed from an unpaired placode, the nasohypophyseal plate, but its primordium always has an indication of a median septum [45-47] which separates the olfactory organ into left and right halves [48]. This septum disappears in adult hagfishes, but retains in adult lampreys [13,49]. Therefore, to some extent, the olfacory organs can be regarded as paired, but closely associated in cyclostomes. In addition, the presence of paired olfactory nerves and bulbs in all living vertebrates also suggests that the presence of paired olfactory organs represents the ancestral vertebrate condition [49]. This condition may have been establshied in such stem vertebrates as the Cambrian myllokunmingiid Haikouichthys [50-52]. If the key players involved in the development of diplorhiny were already recruited in the common ancestor of all vertebrates, it is intriguing to discuss why the monorhinic condition is developed in cyclostomes.

The history of the olfactory organ is closely associated with that of the adenohypophysis [12]. In lampreys, the olfactory organs and adenohypophysis develop as a median nasohypophyseal plate. Although the $H h$ gene family expresses on the whole nasohypophyseal plate [44], the separation of the nasal placodes is probably constrained by the nasohypophyseal complex. Thus, a fused nasal chamber with a single nostril is developed in the midline. Like lampreys, the nasal and hypophyseal placodes of gnathostomes are also located very close to each other at early developmental stages [53], but the nasal placodes are topologically independent from the hypophysis [32]. As discussed previously, this developmental independence has been regarded as a key innovation for patterning the jaw and pituitary organ because it allows the reorganization of premandibular and mandibular ectomesenchyme in the head [6,27] and the reorganization of adenohypophysis in the oral ectoderm [32]. In gnathostomes, $S h h$ is expressed throughout the ventral diencephalon, the oral ectoderm, and nasal placodes, but its expression is subsequently absent from the nascent Rathke's pouch, creating a Shh boundary within the oral 

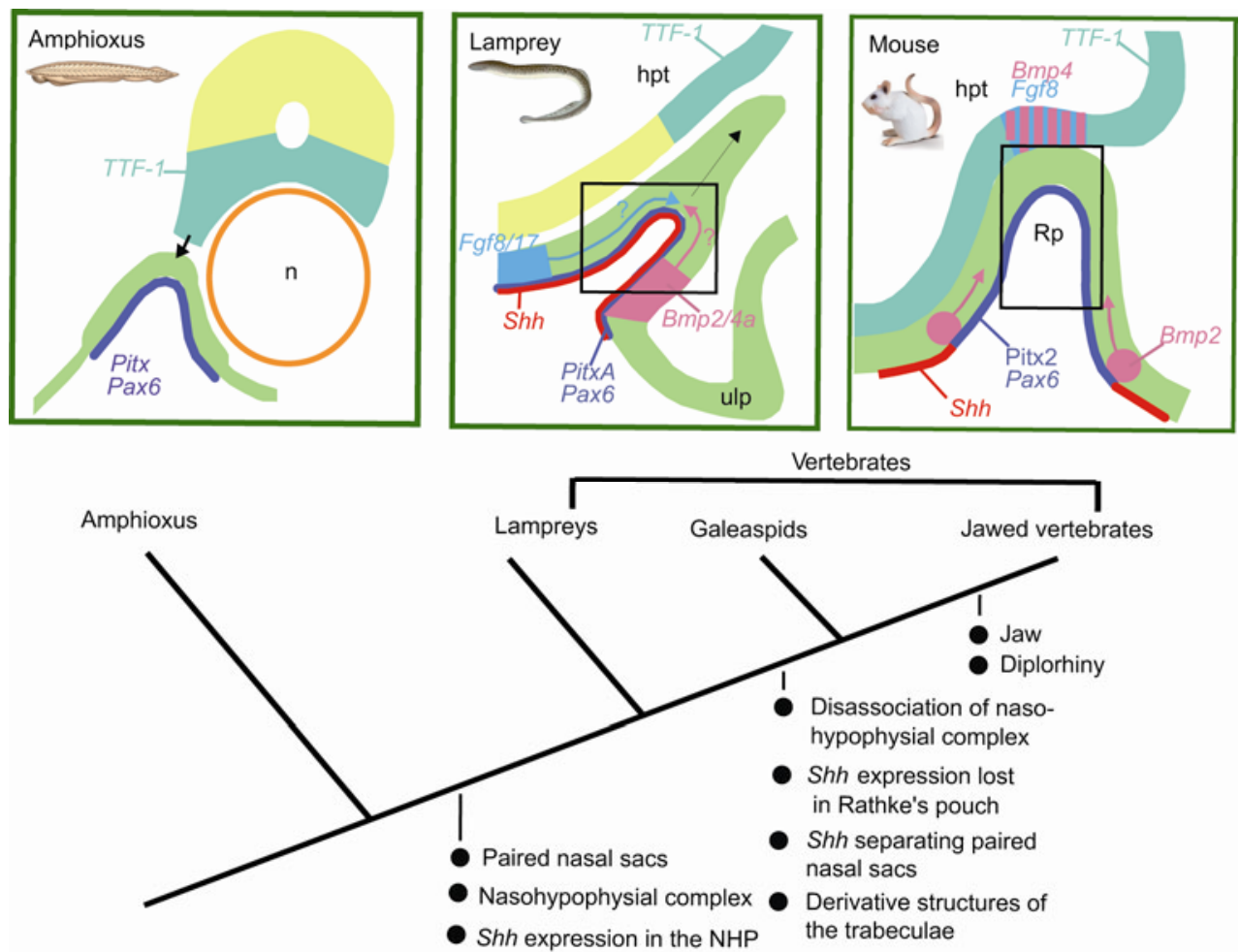

Figure 4 The disassociation of nasohypophyseal complex and the evolution of jaw, diplorhiny, and pituitary. The previously unreported $H h$ expression in the nasohypophyseal plate was observed in lampreys [44], probably indicating that the molecular mechanism separating the nasal sacs has been established in the common ancestor of lampreys and gnathostomes, but their separation was possibly precluded by the nasohypophyseal complex in cyclostomes. The separation of olfactory organs from the adenohypophysis is possibly a crucial innovation for the developmental origin of jaw [6,27] and diplorhiny $[10,12,13]$. Modified from Uchida et al. [32, fig. 8].

epithelium [32,43,54] (Figure 4). In subsequent developmental stages, the paired nasal placodes and the Rathke's pouch are soon separated from each other. Kawamura and Kikuyama [55] and Gleiberman et al. [56] attributed this fast separation possibly partly to the rostral growth of the part of the brain that vertically induces Rathke's pouch. Considering that the paired nasal placodes will form a fused nasal chamber in Shh mutant mice embryos [43], here, we suspect that this fast separation possibly has some relationship to the Shh expression on the nasal placodes establishing their lateral positions. If so, the disconnection of the olfactory placodes from the hypophyseal tube might be a key innovation for the $H h$ gene family to establish the lateral position of nasal sacs before the rise of the diplorhiny, as well as before the origin of the jaw.

\section{Intersection with fossil evidence: galeaspid head innovation}

Compared with the only living jawless vertebrates (hagfishes and lampreys), the extinct jawless ancestors of jawed vertebrates, or 'ostracoderms' were diverse and flourishing during the Silurian and Devonian periods [12,57]. These extinct groups have been consistently resolved as the stem groups of gnathostomes (stem gnathostomes, Figure 1) and provide grounds to establish the sequence in which gnathostome characters appeared [12-15,58-61]. Among these 'ostracoderms', the 420-370-million-year-old osteostracans have been regarded as the closest jawless relatives of the gnathostomes (Figure 1) because they share with the latter a number of uniquely derived characters, such as girdle-supported paired fins, cellular perichondral bone, a sclerotic ring and an epicercal tail $[12,13]$. However, their massive, mineralized braincase has a median nasohypophyseal organ resembling the condition in lampreys. Consequently, osteostracans provide little insight into the evolutionary origin of jaw.

Aside from osteostracans, the approximately coeval galeaspids are the only other 'ostracoderm' group whose cranial anatomy can conceivably be determined by virtue of the exceptionally preserved mineralized or calcified skull [11,62]. Using synchrotron radiation X-ray tomographic microscopy, we have elucidated the gross cranial anatomy of galeaspids and provided the earliest fossil evidence for the disassociation of nasohypophyseal complex in vertebrate phylogeny [11]. Our results indicate that the paired nasal sacs (na, Figure 5(b)-(e)) of galeaspids are located laterally in the oronasal cavity (on.c, Figure 5(c)), and the hypophyseal duct (hy.d, Figure 5(a)-(c),(e)) opens anteriorly 

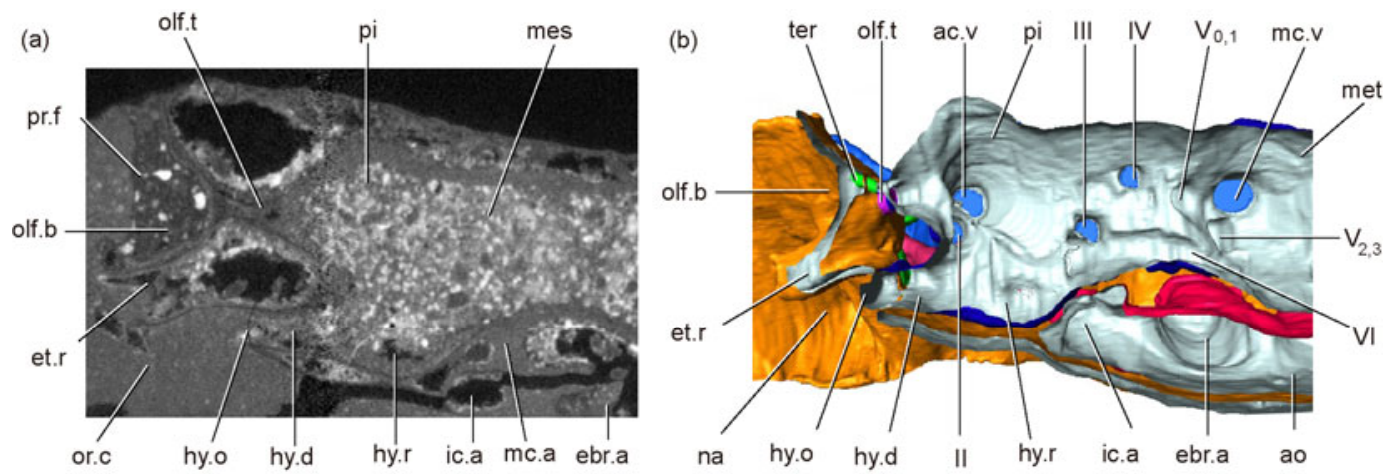

(c)

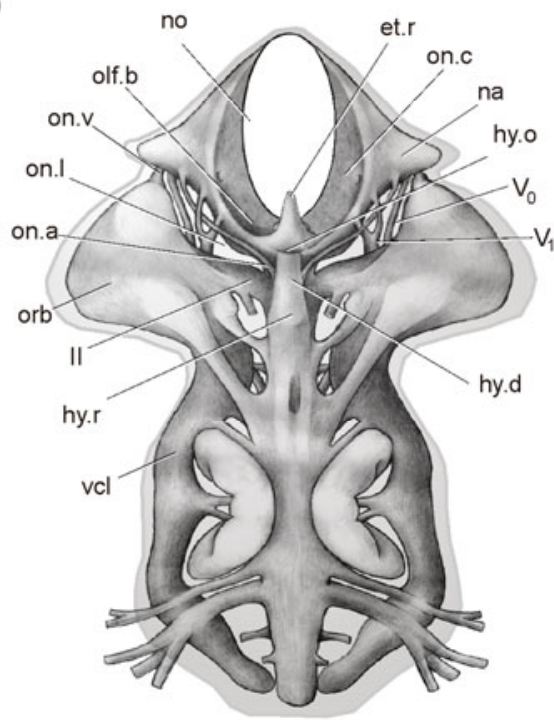

(d)

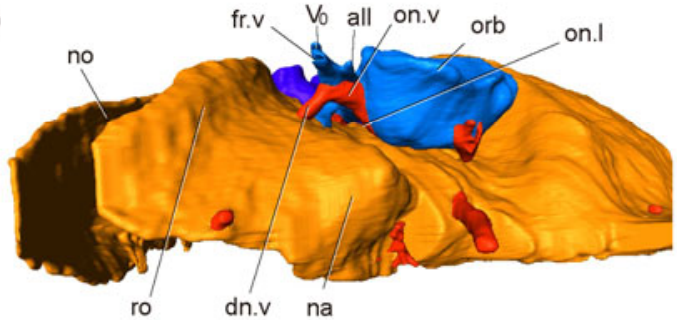

(e)

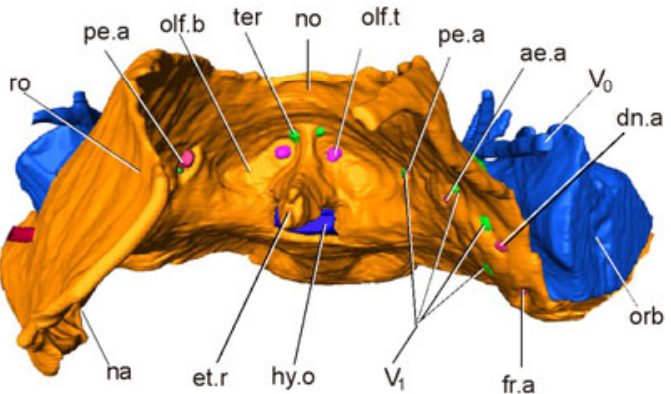

Figure 5 The cranial anatomy of Shuyu zhejiangensis, a 430-million-year-old jawless fish from Zhejiang, China. The derivative structures of the trabeculae (rostrum, orbitonasal lamina, ethmoid plate) and the relative nervous and vascular canals such as the superficial ophthalmic nerve, profundus nerve, orbitonasal artery, and orbitonasal vein are shown by the synchrotron radiation X-ray tomography and restoration. (a) The 512th of 1024 sagittal slices of V14334.3. (b) Middle sagittal section through the braincase (V14334.3), showing the relationship between the hypophyseal duct and the nasal sacs. (c) Restoration for the endocast of the braincase, ventral view. (d) Virtual endocast of the skull, anterolateral view, reconstructed from V14334.1. (e) 3D reconstruction of ethmoid region, frontal view, reconstructed from V14334.3. ac.v, anterior cerebral vein; ae.a, anterior ethmoidal artery; all, anterior lateral line nerve; ao, dorsal aorta; dn.a, dorsal nasal artery; dn.v, dorsal nasal vein; ebr.a, efferent branchial artery; et.r, ethmoid rod; fr.a, frontal artery; fr.v, frontal vein; hy.r, hypophyseal recess; ic.a, internal carotid artery; mc.a, middle cerebral artery; mc.v, middle cerebral vein; mes, mesencephalic division; met, metencephalic division; olf.t, olfactory tract; on.a, orbitonasal artery; on.c, oronasal cavity; on.1, orbitonasal lamina; on.v, orbitonasal vein; orb, orbital opening; or.c, oral cavity; pe.a, posterior ethmoidal artery; pi, pineal organ; pr.f, precerebral fenestra; ro, rostrum; ter, terminal nerve; vcl, lateral head vein or dorsal jugular vein; II, III, IV, $\mathrm{V}_{0}, \mathrm{~V}_{1}, \mathrm{~V}_{0,1}, \mathrm{~V}_{2,3}$, VI, optic (II), oculomotor (III), trochlear (IV), superficial ophthalmic ( $\mathrm{V}_{0}$ ), profundus ( $\mathrm{V}_{1}$ ), superficial ophthalmic plus profundus $\left(\mathrm{V}_{0,1}\right)$, maxillomandibular $\left(\mathrm{V}_{2,3}\right)$ of trigeminal $(\mathrm{V})$, and abducens $(\mathrm{VI})$. See Figure 3 for other abbreviations.

to the oronasal cavity in the middle of the head. Thus, these three structures are independent of each other, as in jawed vertebrates, rather than collocated, like the median nasohypophyseal complex of cyclostomes (hagfishes and lampreys) and osteostracans. Galeaspids, therefore, possessed the condition that current developmental models regard as the prerequisite for the development of jaws. Here, we further describe some derivative structures of the trabeculae (e.g. orbitonasal lamina, ethmoid plate) in galeaspids, which are speculated to be found in some jawless fossil ancestors of jawed vertebrates by the heterotopy theory [27].

Galeaspids are characterized by a large median dorsal opening (no, Figure 5(c)-(e)) in the anterior part of the head (ethmoid region) that serves as both a common nostril and the main water intake device. In the ethmoid region, the large oval-shaped median dorsal opening is flanked by a pair of scoop-like cartilage for the rostrum (ro, Figure 5(d), (e)). Beneath the median dorsal opening is a large median oronasal cavity (on.c, Figure 5(c)) that opens ventrally to the mouth (m, Figure 3(d)) and caudally towards the pharynx (pha, Figure 3(d)). The nasal sacs (na, Figure 5(e)) are paired, large, cone-shaped, and located lateral to the base of the rostrum in the oronasal cavity. As the paired nasal sacs are located antero-lateral to the orbital cavity (orb, Figure 5(c)-(e)), a pair of large cartilaginous plates for the orbitonasal lamina (on.1, Figure 5(c),(d)) are present between 
the nasal sacs and orbital cavities which form the posterolateral walls of nasal sacs and anterior walls of orbital cavities as in gnathostomes. Like gnathostomes, the orbitonasal lamina is penetrated by the diagnostic nervous and vascular canals such as the superficial ophthalmic nerve $\left(\mathrm{V}_{0}\right.$, Figure $5(\mathrm{c})-(\mathrm{e}))$, profundus nerve $\left(\mathrm{V}_{1}\right.$, Figure $\left.5(\mathrm{c})-(\mathrm{e})\right)$, orbitonasal artery (on.a, Figure 5(c)-(e)), and orbitonasal vein (on.v, Figure 5(c)-(e)).

Medially, the orbitonasal lamina protrudes rostrally into the oronasal cavity as the ethmoid process (et.r, Figure 5(a), (b),(e)). The ethmoid process supports and partly floors the paired olfactory bulbs (olf.b, Figure 5(a)-(c),(e)). Compared to gnathostomes, the ethmoid plate of galeaspids is so small that it does not extend rostrally enough to separate the nasal sacs completely (nasal septum not formed). The rostrum, the orbitonasal lamina and the ethmoid plate are regarded as the main derivative structures of the trabeculae in gnathostomes. Their identification in galeaspids indicates that galeaspids at least partly possessed the gnathostome-like trabeculae. The trabeculae cranii of jawed vertebrates has long been regarded as a major evolutionary advance over agnathans [34]. Although the 'trabeculae' of cyclostomes has been reported $[63,64]$, the 'lamprey trabecula' surrounds the hypophysis and extends anteriorly to the olfactory capsules. They are lateral rather than anterior to the notochord [65], and probably represent the anterior prolongation of parachordal cartilage [64,66]. The developmental data indicate that the 'lamprey trabecula' develops from the mandibular mesoderm, and is not homologous with the gnathostome trabecula, which develops from premandibular neural crest cells [27]. Although the developmental process is impossible to access in fossil jawless vertebrates, the presence of trabeculae cranii can be identified by its derivative structures. The nasohypophysial complex in osteostracans is also separated from the orbits by the cartilage, however this chondrous septum is located medial to the orbits and far behind the mandibular arch, and even the hyoid arch [12,13]. In gnathostomes, all derivative structures of the trabeculae (e.g. orbitonasal lamina, ethmoid plate) are developed from the premandibular neural crest. They are topologically rostral to the mandibular arch which is derived from the mandibular neural crest $[6,27]$. Therefore, the cartilage enclosing the nasohypophysial complex in osteostracans hardly corresponds to any derivative structures of the trabeculae. It is more likely to be the anterior prolongation of parachordal cartilage as in lampreys. As there is no mineralized or calcified endoskeletal skull preserved in other 'ostracoderms', the presence of trabecula remains unclear in these groups. Thus, galeaspids might provide the first evidence for the gnathostome-like trabeculae in jawless fishes.

Our result indicates that galeaspids are, in many respects, a better proxy than osteostracans for reconstructing the pre-gnathostome condition of the rostral part of the braincase. Aside from the presence of orbitonasal lamina and ethmoid plate, galeaspids also share with gnathostomes some uniquely derived characters such as separate olfactory bulbs, independent olfactory tracts, terminal nerves, paired separate nasal sacs, the disassociation of nasohypophyseal complex, and the hypophyseal duct opening to the oral cavity $[11,62]$. This raises the potential possibility that galeaspids might be the closest jawless relatives of jawed vertebrates (Figure 3), and will add to our understanding of the early evolution of jawed vertebrates.

\section{Conclusions}

(1) Some derivative structures of the trabeculae (e.g. orbitonasal lamina, ethmoid plate) in jawless galeaspids provide new insights into the reorganization of the vertebrate head before the evolutionary origin of the jaw.

(2) The paired olfactory organs and the molecular mechanism for the separation of nasal sacs might have been established in the common ancestor of lampreys and gnathostomes, but their separation was probably precluded by the nasohypophyseal complex in cyclostomes. The separation of olfactory organs from the adenohypophysis is possibly a crucial innovation for the $H h$ gene family to establish the lateral position of nasal sacs before the rise of the diplorhiny.

(3) Galeaspids provide the earliest evidence for the clear separation of the olfactory organs from the hypophyseal duct in vertebrate phylogeny, a prerequisite condition in evolutionary developmental models for the origin of the jaw [6,27] and diplorhiny [12,13]. Galeaspids display an intermediate condition in the establishment of diplorhiny and jaw in which the barrier to the forward growth of neuralcrest-derived craniofacial ectomesenchyme was removed. As evidenced by galeaspids, this event happened at least 435 million years ago.

(4) No fossil evidence indicates that the diplorhinic condition (nasal sacs with individual externalized nostrils) has been established before the invention of the jaw, but an intermediate condition, paired laterally positioned nasal sacs and independent hypophyseal organ appeared in jawless galeaspids. The complete diplorhiny and the jaw arose later in the lineage leading to the extinct placoderms and the crown-group gnathostomes.

(5) Galeaspids are, in many ways, a better proxy than osteostracans for reconstructing the pre-gnathostome condition of the rostral part of the braincase. This raises the potential possibility that galeaspids might be the closest jawless relatives of jawed vertebrates.

(6) In absence of any evidence for increasingly active feeding strategies that are commonly invoked to explain the origin of the jawed vertebrates [35,36], galeaspids provide evidence that the assembly of gnathostome characters accrued piecemeal before the origin of the jaw rather than as bursts of innovations. 
We thank P. Janvier, P. Donoghue, M. M. Chang, S. Kuratani, J. Maisey, Q. M. Qu and J. H. Xiao for discussions, X. B. Yu and P. Ahlberg for reviewing the manuscript, $F$. X. Wu for the drawing of Figure 5(c). This work was supported by the National Natural Science Foundation of China (40930208), the National Basic Research Program of China (2012CB821902), the Knowledge Innovation Program of the Chinese Academy of Sciences (KZCX2-YW-156), and the CAS/SAFEA International Partnership Program for Creative Research Teams.

1 Maisey J G. Discovering Fossil Fishes. New York: Henry Holt and Company, 1996. 1-223

2 Kimmel C B, Miller C T, Keynes R J. Neural crest patterning and the evolution of the jaw. J Anat, 2001, 199: 105-119

3 Manzanares M, Nieto M A. A celebration of the new head and an evaluation of the new mouth. Neuron, 2003, 37: 895-898

4 Mallatt J. The origin of the vertebrate jaw: Neoclassical ideas versus newer, development-based ideas. Zool Sci, 2008, 25: 990-998

5 Nelson J S. Fishes of the World. 4th ed. New York: Wiley, 2006. $1-624$

6 Kuratani S, Nobusada Y, Horigome N, et al. Embryology of the lamprey and evolution of the vertebrate jaw: Insights from molecular and developmental perspectives. Phil Trans R Soc B, 2001, 356: 1615-1632

7 Heimberg A M, Cowper-Sallari R, Sémon M, et al. MicroRNAs reveal the interrelationships of hagfish, lampreys, and gnathostomes and the nature of the ancestral vertebrate. Proc Natl Acad Sci USA, 2010, 107: 19379-19383

8 Janvier P. MicroRNAs revive old views about jawless vertebrate divergence and evolution. Proc Natl Acad Sci USA, 2010, 107: 19137-19138

9 Kuratani S, Kuraku S, Murakami Y. Lamprey as an evo-devo model: Lessons from comparative embryology and molecular phylogenetics. Genesis, 2002, 34: 175-183

10 Janvier P. Homologies and evolutionary transitions in early vertebrate history. In: Anderson J S, Sues H D, eds. Major Transitions in Vertebrate Evolution. Bloomington and Indianapolis: Indiana University Press, 2007. 57-121

11 Gai Z K, Donoghue P C J, Zhu M, et al. Fossil jawless fish from China foreshadows early jawed vertebrate anatomy. Nature, 2011, 476: 324-327

12 Janvier P. Ostracoderms and the shaping of the gnathostome characters. In: Ahlberg P, ed. Major Events in Early Vertebrate Evolution: Palaeontology, Phylogeny, Genetics and Development. London: Taylor Francis, 2001. 172-186

13 Janvier P. Early Vertebrates. Oxford: Clarendon Press, 1996. 1-393

14 Forey P L. Agnathans recent and fossil, and the origin of jawed vertebrates. Rev Fish Biol Fish, 1995, 5: 267-303

15 Donoghue P C J, Forey P L, Aldridge R J. Conodont affinity and chordate phylogeny. Biol Rev, 2000, 75: 191-251

16 Donoghue P C J, Sansom I J, Downs J P. Early evolution of vertebrate skeletal tissues and cellular interactions, and the canalization of skeletal development. J Exp Zool B Mol Dev Evol, 2006, 306: 278-294

17 Long J A, Brian K H, McNamara K J, et al. The phylogenetic origin of jaws in vertebrates: Developmental plasticity and heterochrony. Kirtlandia, 2010, 57: 46-52

18 Goette, A. Über die Kiemen der Fische. Z Wiss Zool, 1901, 69: 533-577

19 Schaeffer B, Thomson K S. Reflections on agnathan-gnathostome relationships. In: Jacobs L L, ed. Aspects of VertebrateHistory: Essays in Honor of Edwin Harris Colbert. Flagstaff: Museum of Northern Arizona Press, 1980. 19-33

20 Jarvik E. Basic Structure and Evolution of Vertebrates, Volume 1, London: Academic Press, 1980. 1-575

21 Jarvik E. Basic Structure and Evolution of Vertebrates, Volume 2, London: Academic Press, 1980. 1-337

22 Mallatt J. Early vertebrate evolution: Pharyngeal structure and the origin of gnathostomes. J Zool, 1984, 204: 169-183
23 Janvier P. Patterns of diversity in the skull of jawless fishes. In: Hanken J, Hall B K, eds. The Skull. Chicago: University of Chicago Press, 1993. 131-188

24 Janvier P. The phylogeny of the Craniata, with particular reference to the significance of fossil "agnathans". J Vertebr Paleontol, 1981, 1: 121-159

25 Mazan S, Jaillard D, Baratte B, et al. Otx1 gene-controlled morphogenesis of the horizontal semicircular canal and the origin of the gnathostome characteristics. Evol Dev, 2000, 2: 186-193

26 Gegenbaur C. Untersuchungen zur Vergleichenden Anatomie der Wirbeltiere. 3: Das Kopfskelett der Selachier. Leipzig: Englemann, 1872

27 Kuratani S. Evolution of the vertebrate jaw: Comparative embryology and molecular developmental biology reveal the factors behind evolutionary novelty. J Anat, 2004, 205: 335-347

28 Kuratani S. Evolution of the vertebrate jaw: Homology and developmental constraints. Paleontol Res, 2003, 7: 89-102

29 Kuratani S, Murakami Y, Nobusada Y, et al. Developmental fate of the mandibular mesoderm in the lamprey, Lethenteron japonicum: Comparative morphology and development of the gnathostome jaw with special reference to the nature of the trabecula cranii. J Exp Zool B Mol Dev Evol, 2004, 302: 458-468

30 Shigetani Y, Sugahara F, Kawakami Y, et al. Heterotopic shift of epithelial-mesenchymal interactions in vertebrate jaw evolution. Science, 2002, 296: 1316-1319

31 Shigetani Y, Sugahara F, Kuratani S. A new evolutionary scenario for the vertebrate jaw. BioEssays, 2005, 27: 331-338

32 Uchida K, Murakami Y, Kuraku S, et al. Development of the adenohypophysis in the lamprey: Evolution of epigenetic patterning programs in organogenesis. J Exp Zool B Mol Dev Evol, 2003, 300: 32-47

33 Zhu M, Gai Z K. Phylogenetic relationships of galeaspids (Agnatha). Front Biol China, 2007, 2: 151-169

34 Maisey J G. Heads and tails: A chordate phylogeny. Cladistics, 1986, 2: 201-256

35 Gans C, Northcutt R G. Neural crest and the origin of the vertebrates: A new head. Science, 1983, 220: 268-274

36 Baker C V H, Schlosser G. Editorial: The evolutionary origin of neural crest and placodes. J Exp Zool B Mol Dev Evol, 2005, 304B: 269-273

37 Kuratani S. Cephalic neural crest cells and the evolution of craniofacial structures in vertebrates: Morphological and embryological significance of the premandibular-mandibular boundary. Zoology, 2005, 108: 13-25

38 Takio Y, Pasqualetti M, Kuraku S, et al. Lamprey Hox genes and the evolution of jaws. Nature, 2004, 429, doi: 10.1038/nature02616

39 Cohn M J. Lamprey Hox genes and the origin of jaws. Nature, 2002, 416: 386-387

40 Depew M J, Lufkin T, Rubenstein J L R. Specification of jaw subdivisions by $D l x$ genes. Science, 2002, 298: 381-385

41 Varjosalo M, Taipale J. Hedgehog: Functions and mechanisms. Genes Dev, 2008, 22: 2454-2472

42 Chiang C, Ying L, Lee E, et al. Cyclopia and defective axial patterning in mice lacking Sonic hedgehog gene function. Nature, 1996, 383: 407-413

43 Cooper M K. Teratogen-mediated inhibition of target tissue response to Shh signaling. Science, 1998, 280: 1603-1607

44 Kano S, Xiao J H, Osório J, et al. Two lamprey hedgehog genes share non-coding regulatory sequences and expression patterns with gnathostome hedgehogs. PLoS One, 2010, 5: e13332

45 von Kupffer C. Studien zur Vergleichenden Entwicklungsgeschichte des Kopfes der Kranioten. Heft 4: zur Kopfentwicklung von Bdellostoma. München und Leipzig: Verlag von J. F. Lehmann, 1900. $1-86$

46 Stensiö E A. The cyclostomes with special reference to the diphyletic origin of the Petromyzontida and Myxinoidea. In: Ørvig T, ed. Current Problems of Lower Vertebrate Phylogeney. Nobel Symposium 4, Stockholm: Almqvist \& Wiksell, 1968. 13-70

47 Goodrich E S. Studies on the Structure and Development of Vertebrates. London: Macmillan, 1930 
48 Jefferies R P S. The Ancestry of the Vertebrates. London: British Museum (Natural History), 1986

49 Northcutt R G. The brain and sense organs of the earliest vertebrates: Reconstruction of a morphotype. In: Foreman R, Gorbman A, Dodd J, et al. eds. Evolutionary Biology of Primitive Fishes. New York: Plenum Press, 1985. 81-112

50 Shu D G, Conway Morris S, Han J, et al. Head and backbone of the Early Cambrian vertebrate Haikouichthys. Nature, 2003, 421: 526-529

51 Shu D G, Luo H L, Conway Morris S, et al. Lower Cambrian vertebrates from south China. Nature, 1999, 402: 42-46

52 Janvier P. Vertebrate characters and the Cambrian vertebrates. C R Palevol, 2003, 2: 523-531

53 Couly G F, Le Douarin N M. Mapping of the early neural primordium in quail-chick chimeras. I. Developmental relationships between placodes, facial ectoderm, and prosencephalon. Dev Biol, 1985, 110 : 422-439

54 Treier M, Shawn O, Anatoli G, et al. Hedgehog signaling is required for pituitary gland development. Development, 2001, 128: 377-386

55 Kawamura K, Kouki T, Kawahara G, et al. Hypophyseal development in vertebrates from amphibians to mammals. Gen Comp Endocrinol, 2002, 126: 130-135

56 Gleiberman A S, Fedtsova N G, Rosenfeld M G. Tissue interactions in the induction of anterior pituitary: Role of the ventral diencephalon, mesenchyme, and notochord. Dev Biol, 1999, 213: 340-353

57 Zhao W J, Zhu M. Diversification and faunal shift of Siluro-Devonian vertebrates of China. Geol J, 2007, 42: 351-369

58 Forey P L, Janvier P. Agnathans and the origin of jawed vertebrates. Nature, 1993, 361: 129-134

59 Janvier P. The dawn of the vertebrates: Characters versus common ascent in the rise of current vertebrate phylogenies. Palaeontology, 1996, 39: 259-287

60 Donoghue P C J, Smith M P. The anatomy of Turinia pagei (Powrie), and the phylogenetic status of the Thelodonti. Trans R Soc Edinb Earth Sci, 2001, 92: 15-37

61 Gess R W, Coates M I, Rubidge B S. A lamprey from the Devonian period of South Africa. Nature, 2006, 443: 981-984

62 Wang N Z. Two new Silurian galeaspids (jawless craniates) from Zhejiang Province, China, with a discussion of galeaspid-gnathostome relationships. In: Chang M M, Liu Y H, Zhang G R, eds. Early Vertebrates and Related Problems of Evolutionary Biology. Beijing: Science Press, 1991. 41-66

63 Damas H. Recherches sur le développement de Lampetra fluviatilis L. Contribution a l'étude de la céphalogenese de Vertébrés. Arch Biol, 1944, 55: 1-285

64 Johnels A G. On the development and morphology of the skeleton of the head of Petromyzon. Acta Zool, 1948, 29: 139-279

65 Jollie M. Chordate Morphology. New York: Reinhold Books, 1962. $1-478$

66 de Beer G R. The Development of the Vertebrate Skull. Oxford: Oxford University Press, 1937

Open Access This article is distributed under the terms of the Creative Commons Attribution License which permits any use, distribution, and reproduction in any medium, provided the original author(s) and source are credited. 